\title{
Quadratic demand, Variable holding cost with Time Dependent Deterioration without Shortages and Salvage Value
}

\author{
R. Mohan \\ Dept. of Mathematics College of Military Engineering Pune-31-Maharastra-INDIA
}

\begin{abstract}
In this paper, an attempt has been made to study deterministic inventory models for deteriorating items with variable holding cost. This model has been developed considering demand function as quadratic with respect to time and salvage value is associated to the deteriorated items. At the end numerical example with sensitivity analysis also presented.
\end{abstract}

Key Words: Variable holding cost, Deterioration, Quadratic demand, Inventory

\section{Introduction}

Researchers developed exponentially increasing/decreasing growth in demand for any commodity. This phenomenon is not realistic for any item. Also the rate of linear-time varying demand has some limitations, i.e., uniform change in demand rate per unit time. This is not quite frequent in any case of items/commodity in business. In general for realistic situation, addressing demand rate in quadratic demand pattern (Khanra and Chaudhuri, 2003) is quite worthy than exponential demand rate or linear demand rate.

Hariga (1995) studied an EOQ model with time-varying demand with shortages for deteriorating items. Chakraborti and Choudhuri (1996) proposed an EOQ model in linear trend in demand with shortages in all cycles for deteriorating products. Giri and Chaudhuri (1997) presented an EOQ model for deteriorating items of time varying demand and costs. Shortages are considered in the demand rate. Goyal and Giri (2001) studied survey of recent trend in deteriorating inventory models considering various types of demand rate. Mondal et. al (2003) developed price dependent demand rate of an inventory model for ameliorating items. Ajanta Roy (2008) proposed an inventory model with and without shortages of price dependent demand for deteriorating items incorporating time varying holding cost. Mishra and Singh (2010) studied an inventory model with partial backlogging of time dependent demand rate for deteriorating items. Sushil Kumar and U.S. Rajput (2013) studied an inflationary inventory model with constant demand considering Weibull rate of deterioration and partial backlogging under permissible delay in payments. R. Amutha and Dr.E. Chandrasekaran proposed an inventory model for constant demand with shortages under permissible delay in payments. In this model they incorporated deterioration rate with respect to time. Venkateswarlu and Mohan (2013a) studied an EOQ model for price dependent quadratic demand with time varying deterioration under salvage value for deteriorating items. Venkateswarlu and Mohan (2013b) studied an EOQ model with Weibull deterioration (2-Parameter), time dependent quadratic demand and salvage value for deteriorating items. Mohan and Venkateswarlu (2013a) studied an EOQ models with holding cost as function of time and salvage value. Mohan and Venkateswarlu (2013b) proposed an inventory model for, quadratic demand as a function of time with salvage value for deteriorating products considering deterioration rate is time dependent. Recently, Mohan and Venkateswarlu (2013c) proposed an EOQ model with Quadratic Demand, considering Holding Cost as function of time with Salvage value.

In this paper, inventory models have been developed using variable holding cost when the demand rate is a quadratic function of time with time-dependent deterioration. Shortages are not allowed and the time horizon is infinite. The optimal total cost (TC) is obtained by considering the salvage value for deteriorated items. Numerical example and sensitivity analysis is also carried out.

\section{Assumptions And Notations}

The following assumptions and notations are used to develop in this mathematical model:

The rate of demand $\mathrm{D}(\mathrm{t})$ at time $t$ is assumed to be $D(t)=a+b t+c t^{2}, a \geq 0, b \neq 0, c \neq 0$

(i) Replenishment rate is infinite.

(ii) $\theta(t)=\theta t$ is the deterioration rate, $0<\theta<1$.

(iii) $\quad \mathrm{C}$, the cost per unit

(iv) $\quad(h+\beta t), \quad 0<\beta<1$, the carrying cost per unit

(v) $A$ is the order cost per unit order.

(vi) $\quad I(t)$ is the inventory level at time $t$.

(vii) Lead time is zero. 
(viii) $\mathrm{Q}_{1}$, order quantity in one cycle

(ix) The salvage value $\gamma \mathrm{C}, 0 \leq \gamma<1$ is associated with deteriorated units during a cycle time.

\section{Mathematical And Solution Of The Model}

The differential equation which governs the inventory level at time $t$ is given by

$$
\frac{d Q(t)}{d t}+\theta t Q(t)=-\left(a+b t+c t^{2}\right), \quad 0 \leq t \leq T
$$

with the initial condition $Q(0)=Q_{l}$ and $Q(T)=0$.

Equation (1) is a linear first order differential equation which can be written as

$$
\left(Q(t) e^{\frac{\theta t^{2}}{2}}\right)^{\prime}=-\left(a+b t+c t^{2}\right) e^{\frac{\theta t^{2}}{2}}
$$

which on integration yields

$$
Q(t)=-e^{-\frac{\theta t^{2}}{2}} \int\left(a+b t+c t^{2}\right) e^{\frac{\theta t^{2}}{2}} d t+k_{l} e^{\frac{-\theta t^{2}}{2}}
$$

where $k_{l}$ is an integral constant.

Using initial conditions and expanding $e^{\frac{\theta t^{2}}{2}}$ by omitting the higher order terms involving $\theta$ (not more than $2^{\text {nd }}$ power terms), the solution of the above equation is obtained as

$$
\begin{aligned}
& \left\{\begin{array}{l}
\left\{a(T-t)+\frac{b\left(T^{2}-t^{2}\right)}{2}+\frac{c\left(T^{3}-t^{3}\right)}{3}\right\} \\
+\theta\left\{\frac{a\left(T^{3}-t^{3}\right)}{6}+\frac{b\left(T^{4}-t^{4}\right)}{8}+\frac{c\left(T^{5}-t^{5}\right)}{10}\right\}
\end{array}\right. \\
& Q(t)=\left\{\begin{array}{l}
+\theta^{2}\left\{\frac{a\left(T^{5}-t^{5}\right)}{40}+\frac{b\left(T^{6}-t^{6}\right)}{48}+\frac{c\left(T^{7}-t^{7}\right)}{56}\right\} \\
-\theta\left(\frac{a\left(t^{2} T-t^{3}\right)}{2}+\frac{b\left(t^{2} T^{2}-t^{4}\right)}{4}+\frac{c\left(t^{2} T^{3}-t^{5}\right)}{6}\right)
\end{array}\right. \\
& -\theta^{2}\left(\frac{a}{12}\left(T^{3} t^{2}-t^{5}\right)+\frac{b}{16}\left(T^{4} t^{2}-t^{6}\right)+\frac{c}{20}\left(T^{5} t^{2}-t^{7}\right)\right) \\
& +\theta^{2}\left(\frac{a}{8}\left(t^{4} T-t^{5}\right)+\frac{b}{16}\left(T^{2} t^{4}-t^{6}\right)+\frac{c}{24}\left(T^{3} t^{4}-t^{7}\right)\right)
\end{aligned}
$$

Using $Q(0)=Q_{l}$, we obtain

$$
Q_{1}=\left[a T+\frac{b T^{2}}{2}+\frac{c T^{3}}{3}+\theta\left(\frac{a T^{3}}{6}+\frac{b T^{4}}{8}+\frac{c T^{5}}{10}\right)+\theta^{2}\left(\frac{a T^{5}}{40}+\frac{b T^{6}}{48}+\frac{c T^{7}}{56}\right)\right]
$$

\section{Inventory Models Without Shortages}

The following costs are taken for consideration to calculate total cost of the system:

Ordering cost $=A$

Material cost per cycle

(Including Deterioration Loss) $=Q(0) C=Q_{1} C$

Carrying cost/holding cost per cycle $=(h+\beta t) \int_{0}^{T} Q(t) d t$

Total Cost $=$ Carrying cost + Ordering cost + Material cost 
$=\frac{A}{T}+\frac{C Q(0)}{T}+\frac{(h+\beta t)}{T} \int_{0}^{T} Q(t) d t$

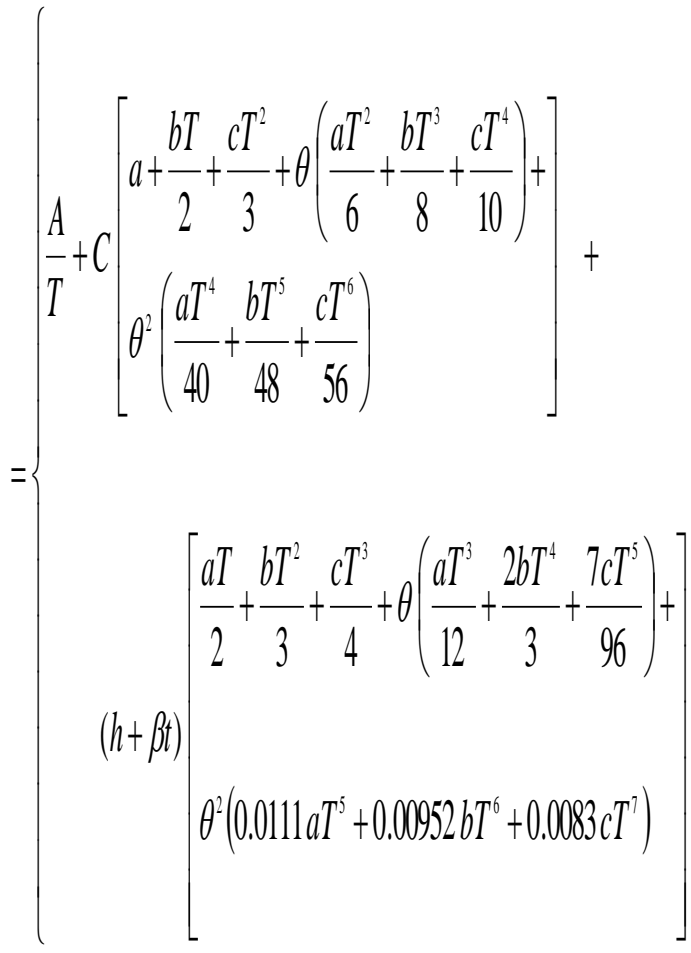

The necessary condition for minimizing the total cost is $\frac{\partial(T C)}{\partial T}=0$, i.e.,

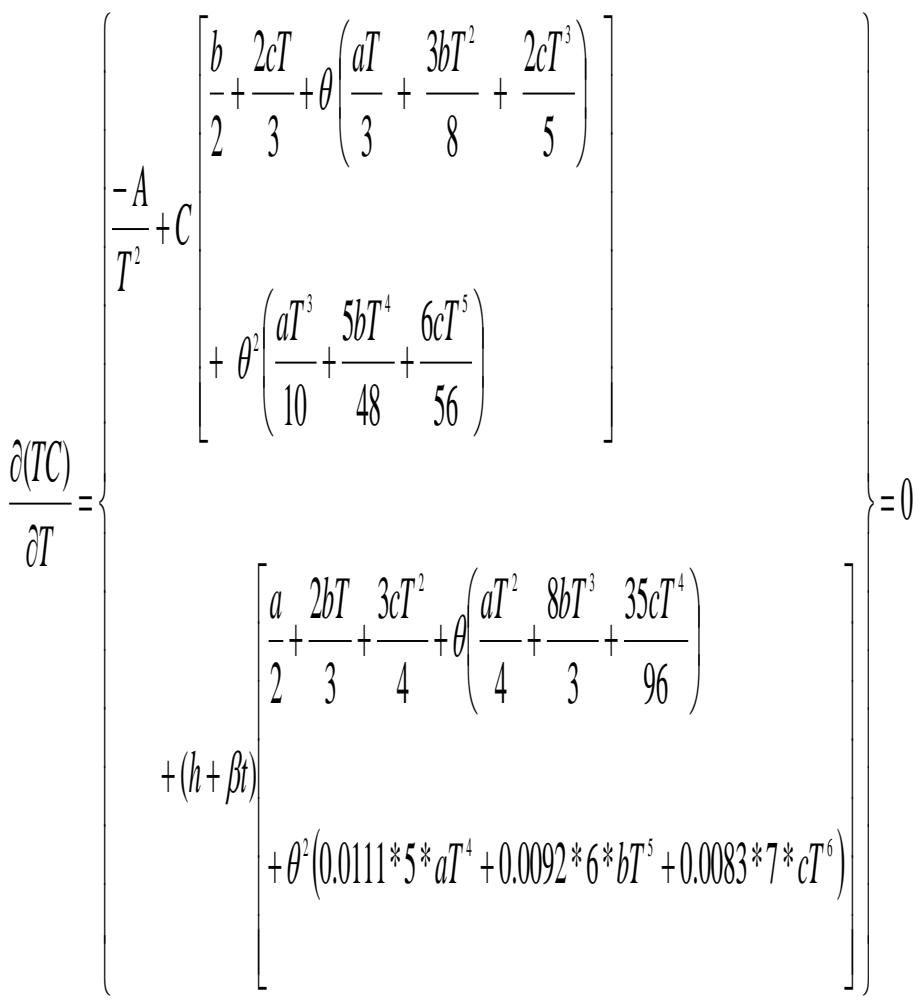


Using MATHCAD the optimal value of $\mathrm{T}$ and the total cost (TC) is obtained from equation (7)

The following numerical example is taken to verify the sufficient condition i.e., $\frac{\partial^{2}(T C)}{\partial T^{2}}>0$. It is found that the optimality conditions are satisfied for all $\mathrm{T}$ in all the four cases viz.,

(i) $c>0$ and $b>0$ gives accelerated growth in demand model (M-1)

(i) $\quad c>0$ and $b<0$ gives retarded growth in demand model (M-2)

(iii) $c<0$ and $b>0$, gives retarded decline in demand model (M-3)

(iv) $\quad c<0$ and $b<0$, gives accelerated decline in demand model (M-4)

\subsection{Numerical Example}

We now consider an inventory system with the following hypothetical values for the parameters:

$\mathrm{c}=4, \quad \mathrm{~b}=20, \quad \mathrm{a}=500, \mathrm{~h}=0.6$

$\mathrm{A}=150, \quad \mathrm{C}=3, \quad \theta=0.01, \beta=0.3$

The following tables indicate the MATHCAD output to compare our models with linear demand patterns:

Model-I: $(\mathrm{a}>0, \mathrm{~b}>0$ and $\mathrm{c}>0)$

Table.1:

\begin{tabular}{|l|l|l|l|}
\hline Model Type & T & TC & Q \\
\hline Quad. Demand & 0.79 & 1855.286 & 402.321 \\
\hline Linear Demand & 0.801 & $\begin{array}{l}1852.398 \\
407.355\end{array}$ & \\
& & \\
\hline
\end{tabular}

Model-II: $(\mathrm{a}>0, \mathrm{~b}>0$ and $\mathrm{c}<0)$

Table.2:
\begin{tabular}{|c|c|c|c|}
\hline Model Type & T & TC & Q \\
\hline Quad. Demand & 0.814 & 1849.416 & 413.366 \\
\hline Linear Demand & 0.801 & 1852.398 & 407.355 \\
\hline
\end{tabular}

Model-III: $(\mathrm{a}>0, \mathrm{~b}<0$ and $\mathrm{c}>0)$

Table.3:

\begin{tabular}{|l|c|c|c|}
\hline Model Type & T & TC & Q \\
\hline Quad. Demand & 0.932 & 1797.017 & 459.053 \\
\hline Linear Demand & 0.955 & 1792.847 & 469.086 \\
\hline
\end{tabular}

Model-IV: $(\mathrm{a}>0, \mathrm{~b}<0$ and $\mathrm{c}<0)$

Table.4:

\begin{tabular}{|l|l|l|l|}
\hline Model Type & T & TC & Q \\
\hline Quad. Demand & 0.982 & 1788.434 & 480.857 \\
\hline Linear Demand & 0.955 & 1792.847 & 469.086 \\
\hline
\end{tabular}

Considering Model II and Model IV of these models the conditions of optimality is being satisfied. Hence we take Model II and Model IV for further discussions. The total cost (TC) of these two models is reduced when comparing with linear demand models and quadratic time dependent demand models. In comparison with linear models the lot size and re-order time are more .Thus we conclude that the re-orders become not so frequent and economic lot size will be higher and in both case (i.e., retarded growth and accelerated decline models.)

\subsection{Sensitivity Analysis}

We will analyze the cycle time (T), total cost (TC) and EOQ (Q) by changing the values of the parameters a, b, c, C, A, $\theta$ and altogether from $20 \%$ to $50 \%$ and $-20 \%$ to $-50 \%$ of model- II and model- IV. The observations are as follows from table 5:

(i) $\mathrm{TC}$ and $\mathrm{Q}$ both decreases (increases) while $\mathrm{T}$ increases (decreases) with the decrease (increase) in the parameter values of ' $a$ '.

(ii) $\mathrm{T}$ and $\mathrm{Q}$ increase (decrease) when $\mathrm{TC}$ decreases (increases) with the decrease (increase) in the parameter values of ' $b$ '

(iii) $\mathrm{T}$ and $\mathrm{Q}$ decrease (increase) where as TC increases (decreases) with the decrease (increase) in the parameter ' $c$ ', In the above three cases the sensitivity is very marginal.

(iv) TC decrease (increases) while $\mathrm{T}$ and $\mathrm{Q}$ increases (decreases) when the parameter ' $\mathrm{C}$ ' decrease (increase). The sensitivity is substantial in this case.

(v) All the three values T, TC and Q decreases(increases) with the 
Decrease (increase) in the values of ' $A$ '. In this case the sensitivity rate considered to be high.

(vi) Decrease (increase) in the parameter $\theta, \mathrm{TC}$ decreases (increases) and $\mathrm{T}$ and $\mathrm{Q}$ increase (decrease). In this case sensitivity is very negligible.

It is observed from table-6, the values of total cost (TC), cycle time T, and EOQ (Q) in accelerated decline model also noticed similar changes as earlier retarded growth model when all the parameters are decreased or increased.

It is also observed that the unit cost $\mathrm{C}$ of the commodity towards total cost (TC) is highly sensitive.

Finally the study of sensitivity analysis of both models exhibit similar behavior when the changes made in the parameter values of $a, c, A, C$ and $\theta$ except for the parameter $b$.

Table.5: Model - II:

$(\mathrm{a}>0, \mathrm{~b}>0$ and $\mathrm{c}<0)$
Table.6: Model - IV

$(\mathrm{a}>0, \mathrm{~b}<0$ and $\mathrm{c}<0)$

\begin{tabular}{|c|c|c|c|c|c|c|c|c|}
\hline parameter & $\%$ change & T TC & Q & & $\mathrm{T}$ & TC & $\mathrm{Q}$ & \\
\hline \multirow[t]{4}{*}{$\mathrm{a}$} & -50 & 1.051 & 1018.839 & 272.758 & & 1.687 & 924.726 & 388.639 \\
\hline & -20 & 0.887 & 1519.92 & 362.216 & & 1.13 & 1450.695 & 438.223 \\
\hline & 20 & 0.757 & 2176.391 & 459.793 & & 0.883 & 2121.189 & 521.757 \\
\hline & 50 & 0.692 & 2663.293 & 523.766 & & 0.781 & 2614.269 & 579.601 \\
\hline \multirow[t]{4}{*}{$\mathrm{b}$} & -50 & 0.847 & 1835.33 & 426.788 & & 0.929 & 1804.976 & 459.773 \\
\hline & -20 & 0.827 & 1843.858 & 418.697 & & 0.96 & 1795.178 & 472.166 \\
\hline & 20 & 0.802 & 1854.879 & 408.472 & & 1.006 & 1781.501 & 490.313 \\
\hline & 50 & 0.785 & 1862.905 & 401.515 & & 1.046 & 1770.711 & 505.968 \\
\hline \multirow[t]{4}{*}{$\mathrm{c}$} & -50 & 0.808 & 1850.92 & 410.627 & & 0.968 & 1790.674 & 474.758 \\
\hline & -20 & 0.811 & 1850.021 & 411.963 & & 0.976 & 1789.338 & 478.233 \\
\hline & 20 & 0.817 & 1848.808 & 414.767 & & 0.988 & 1787.518 & 483.472 \\
\hline & 50 & 0.821 & 1847.887 & 416.604 & & 0.997 & 1786.121 & 487.374 \\
\hline \multirow[t]{4}{*}{$\mathrm{C}$} & -50 & 0.837 & 1087.527 & 425.224 & & 0.938 & 1053.553 & 459.768 \\
\hline & -20 & 0.823 & 1544.699 & 418.005 & & 0.964 & 1494.57 & 472.235 \\
\hline & 20 & 0.805 & 2154.084 & 408.729 & & 1.002 & 2082.172 & 490.429 \\
\hline & 50 & 0.792 & 2610.995 & 402.033 & & 1.033 & 2522.526 & 505.246 \\
\hline \multirow[t]{4}{*}{$\mathrm{A}$} & -50 & 0.593 & 1743.025 & 299.915 & & 0.716 & 1700.277 & 352.683 \\
\hline & -20 & 0.736 & 1810.705 & 373.224 & & 0.888 & 1756.351 & 435.747 \\
\hline & 20 & 0.883 & 1884.758 & 448.966 & & 1.066 & 1817.723 & 520.995 \\
\hline & 50 & $\begin{array}{l}0.976 \\
1933.147\end{array}$ & 497.081 & & 1.178 & 1857.815 & 574.251 & \\
\hline \multirow[t]{4}{*}{$\theta$} & -50 & 0.819 & 1848.395 & 415.709 & & 0.992 & 1786.997 & 485.251 \\
\hline & -20 & 0.816 & 1849.01 & 414.304 & & 0.986 & 1787.862 & 482.618 \\
\hline & 20 & 0.812 & 1849.821 & 412.427 & & 0.978 & 1789 & 479.093 \\
\hline & 50 & 0.809 & 1850.425 & 411.016 & & 0.973 & 1789.842 & 476.919 \\
\hline
\end{tabular}

*In table 6, the cycle time (T), Total Cost (TC) and Ordering quantity (Q) is calculated for the same parameter and percentage as considered in table 5

\section{Inventory Models With Salvage}

The number of deteriorated units $(N D U)$ during this cycle time is

$$
N D U=Q-\int_{0}^{T} D(t) d t \text {, where } D(t)=\left(a+b t+c t^{2}\right)
$$

Total Cost $(\mathrm{TC})=$ Inventory Holding cost + Ordering cost + Cost due to deterioration - Salvage value

$$
\begin{aligned}
& T C=\frac{(h+\beta t)}{T} \int_{0}^{T} I(t) d t+\frac{A}{T}+\frac{C}{T}\left[Q-\left(a T+\frac{b T^{2}}{2}+\frac{c T^{3}}{3}\right)\right]-\frac{\gamma^{*} C}{T}\left[Q-\left(a T+\frac{b T^{2}}{2}+\frac{c T^{3}}{3}\right)\right]
\end{aligned}
$$

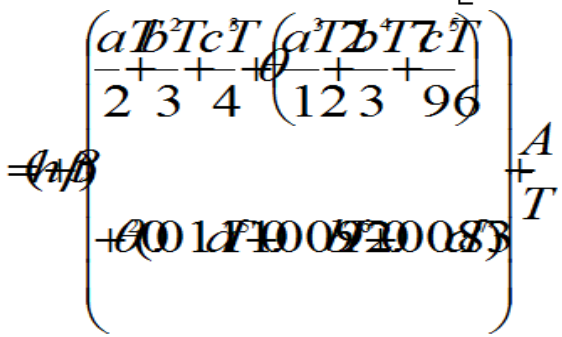

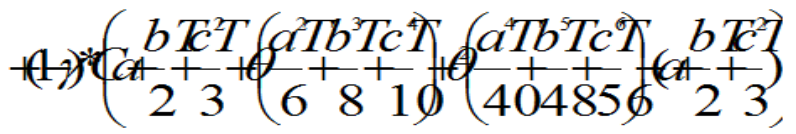


The necessary condition for a minimum total cost per unit time is $\frac{\partial(T C)}{\partial T}=0$

$+(h+\beta t)\left[\begin{array}{c}\left.\left[\begin{array}{l}\frac{a}{2}+\frac{2 b T}{3}+\frac{3 c T^{2}}{4}+\theta\left(\frac{a T^{2}}{4}+\frac{8 b T^{3}}{3}+\frac{35 c T^{4}}{96}\right) \\ +\theta^{2}\left(0.0111 * 5 * a T^{4}+0.0092 * 6 * b T^{5}+0.0083 * 7 * c T^{6}\right)\end{array}\right]+\frac{-A}{T^{2}}\right] \\ +(1-\gamma) * C\left[\frac{b}{2}+\frac{2 c T}{3}+\theta\left(\frac{a T}{3}+\frac{3 b T^{2}}{8}+\frac{2 c T^{3}}{5}\right)+\theta^{2}\left(\frac{a T^{3}}{10}+\frac{5 b T^{4}}{48}+\frac{6 c T^{5}}{56}\right)-\left(\frac{b}{2}+\frac{2 c T}{3}\right)\right.\end{array}\right]=0$

$$
\text { Provided } \frac{\partial^{2}(T C)}{\partial T^{2}}>0 \text { i.e., }
$$

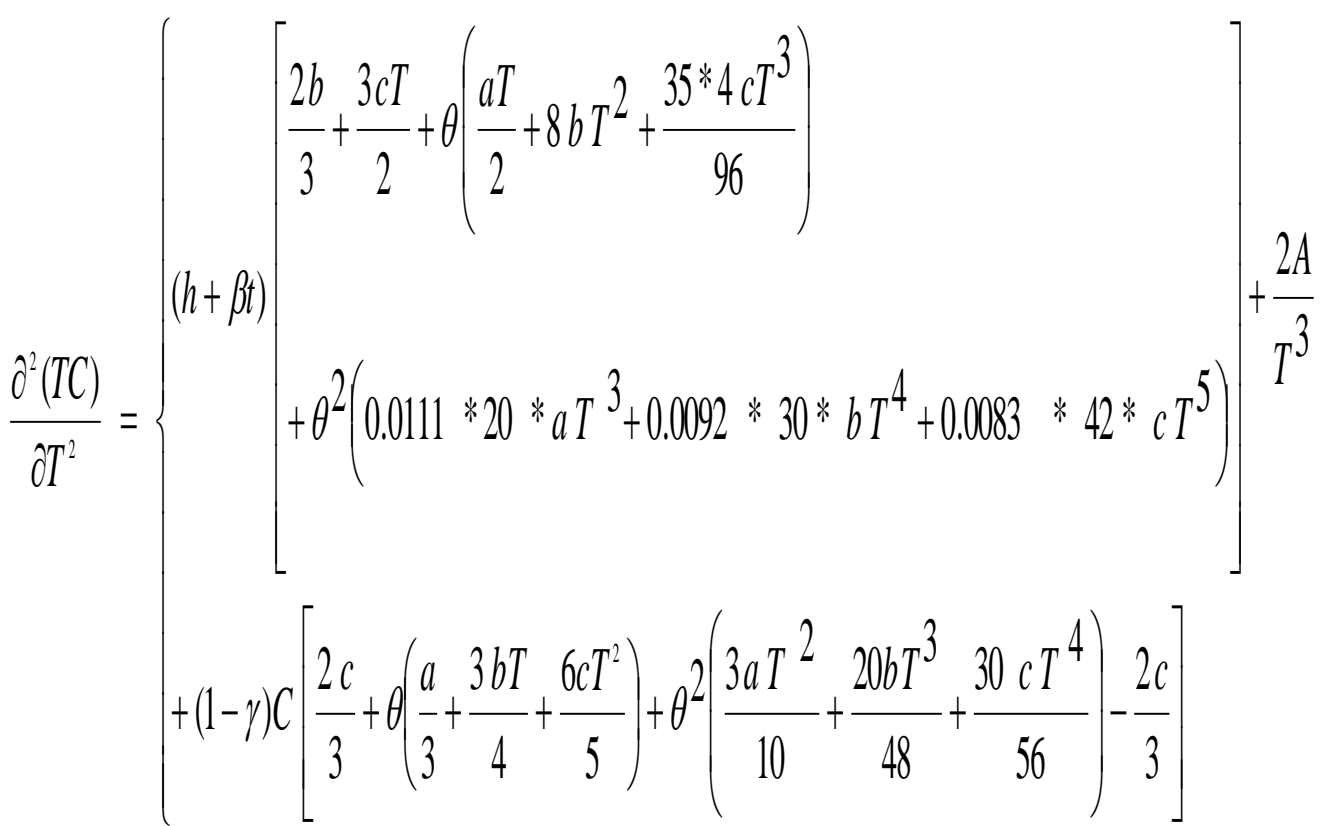

We solved the above two equations for a minimum of TC using MATHCAD. The optimum values of the total cost, re-order time, and lot size are calculated with a numerical example and are shown in the following tables: 


\subsection{Numerical example}

To illustrate the model developed, we have taken the following data:

$\mathrm{a}=500, \mathrm{~b}=20, \mathrm{c}=4$,

$\gamma=0.1$

$\mathrm{A}=150$,

$\mathrm{C}=3$,

$\theta=0.01, \mathrm{i}=0.2$

Model-I: $(\mathrm{a}>0, \mathrm{~b}>0$ and $\mathrm{c}>0)$

Table.7:

\begin{tabular}{|l|c|c|c|c|}
\hline Model Type & T & TC & Q & NDU \\
\hline Quad. Demand & 0.849 & 327.882 & 433.049 & 0.525 \\
\hline Linear Demand & 0.852 & 327.443 & 433.788 & 0.529 \\
\hline
\end{tabular}

Model -II: $(\mathrm{a}>0, \mathrm{~b}<0$ and $\mathrm{c}>0)$

Table.8:

\begin{tabular}{lllll}
\hline Model Type & T & TC & Q & NDU \\
\hline Quad. Demand & 0.883 & 320.737 & 435.182 & 0.561 \\
Linear Demand & 0.887 & 320.24 & 436.199 & 0.567 \\
\hline
\end{tabular}

Model -III: $(\mathrm{a}>0, \mathrm{~b}>0$ and $\mathrm{c}<0)$

Table.9:

\begin{tabular}{|l|c|c|l|c|}
\hline Model Type & T & TC & \multicolumn{1}{c|}{ Q } & NDU \\
\hline Quad. Demand & 0.855 & 327.001 & 434.51 & 0.533 \\
\hline Linear Demand & 0.852 & 327.443 & 433.788 & 0.529 \\
\hline
\end{tabular}

Model -IV: $(\mathrm{a}>0, \mathrm{~b}<0$ and $\mathrm{c}<0)$

Table.10:

\begin{tabular}{|l|l|l|l|l|}
\hline Model Type & \multicolumn{1}{|c|}{ T } & \multicolumn{1}{|c|}{ Q } & \multicolumn{1}{c|}{ Q } & NDU \\
\hline Quad. Demand & 0.891 & 319.736 & 437.19 & 0.572 \\
\hline Linear Demand & 0.887 & 320.24 & 436.199 & 0.567 \\
\hline
\end{tabular}

Model-III and Model-IV from above tables 7-10 it is clear they behave alike. Also it is observed that the changes are very small in both cases. Hence the sensitivity of model-IV is taken for consideration in the following sensitivity Analysis:

\subsection{Sensitivity Analysis}

MODEL IV $(\mathrm{a}>0, \mathrm{~b}<0$ and $\mathrm{c}<0)$

Table.11: Sensitivity of the Salvage parameter $\gamma$

\begin{tabular}{|l|l|l|l|l|}
\hline & T & TC & Q & NDU \\
\hline$\gamma=0.1$ & 0.891 & 319.736 & 437.19 & 0.572 \\
\hline$\gamma=0.15$ & 0.891 & 319.736 & 437.19 & 0.572 \\
\hline$\gamma=0.2$ & 0.892 & 319.543 & 437.671 & 0.574 \\
\hline$\gamma=0.25$ & 0.892 & 319.543 & 437.671 & 0.574 \\
\hline$\gamma=0.3$ & 0.892 & 319.543 & 437.671 & 0.574 \\
\hline
\end{tabular}

Table.12: Sensitivity of the parameter $\boldsymbol{\theta}$

\begin{tabular}{|l|l|l|l|l|}
\hline & $\mathrm{T}$ & $\mathrm{TC}$ & $\mathrm{Q}$ & $\mathrm{NDU}$ \\
\hline $\boldsymbol{\theta}=0.01$ & 0.891 & 319.736 & 437.19 & 0.572 \\
\hline $\boldsymbol{\theta}=0.05$ & 0.851 & 327.721 & 419.943 & 2.507 \\
\hline $\boldsymbol{\theta}=0.1$ & 0.811 & 336.792 & 402.577 & 4.365 \\
\hline $\boldsymbol{\theta}=0.15$ & 0.779 & 345.092 & 388.633 & 5.832 \\
\hline $\boldsymbol{\theta}=0.2$ & 0.752 & 352.788 & 376.803 & 7.025 \\
\hline
\end{tabular}

Table.13: Sensitivity of the parameter $\boldsymbol{\theta}$ and $\gamma$

\begin{tabular}{|l|l|l|l|l|l|}
\hline & & $\mathrm{T}$ & $\mathrm{TC}$ & $\mathrm{Q}$ & $\mathrm{NDU}$ \\
\hline $\boldsymbol{\theta}=0.01$ & $\gamma=0.1$ & 0.891 & 319.736 & 437.19 & 0.572 \\
\hline $\boldsymbol{\theta}=0.05$ & $\gamma=0.15$ & 0.852 & 327.279 & 420.432 & 2.516 \\
\hline $\begin{array}{l}0.79341 .6743 \\
94.1846 .082 \\
\boldsymbol{\theta}=0.1\end{array}$ & $\gamma=0.2$ & 0.817 & 335.165 & 405.561 & 4.463 \\
\hline $\begin{array}{c}\boldsymbol{\theta}=0.2 \gamma= \\
0.25\end{array}$ & $\gamma=0.3$ & 0.77 & 347.048 & 386.005 & \\
$\boldsymbol{\theta}=0.15$ & & & & & \\
\hline
\end{tabular}




\section{Discussion}

Special Case: In both cases as proposed without shortages and Salvage value in this paper When $\beta=0$ i.e., when holding cost is constant the derived model reduces to that of R. Mohan and R. Venkateswarlu, (2014) J.of the Indian math. Soc. Vol 81, Nos 1-2 (2014), 135-146. Hence this model reflects extensive work on variable holding cost as mentioned above.

\section{Conclusions}

The deterministic inventory models are studied for total cost(TC),cycle time $\mathrm{T}$ and economic purchase quantity $(\mathrm{Q})$ for time dependent deterioration rate, time dependent holding cost and time dependent quadratic demand when shortages are not allowed. Here the salvage value is associated to number of deteriorated units during cycle time.

\section{Scope For Further Research:}

This study can consider further research using price dependent demand, Weibull rate of deterioration, constant deterioration, and linear demand rate and permissible delay in payments.

\section{References}

[1]. Ajanta Roy, 2008, An Inventory model for deteriorating items with price dependant demand and time-varying holding cost, AMOAdv modeling and optim, volume 10, number 1

[2]. Amutha R, Chandrasekaran E, (2013), An Inventory Model for constant demand with shortages under permissible delay in payments, IOSR J of Math. (IOSR-JM) Vol 6 issue 5 (May -June 2013),PP 28-33

[3]. Chakraborti T. and Chaudhuri K.S., (1996) An EOQ model for items with linear trend in demand and shortages in all cycles Int. Jour of Production Eco,49,205-213

[4]. Giri B.C and Chaudhuri K.S.,(1997) Heuristic model for deteriorating items with shortages Int. Jour of System Science,28,153-159

[5]. Goyal S.K and Giri. B.C., (2001), Recent trends in modeling of deteriorating inventory European Jour of Ops resh, Vol.134, pp.116.

[6]. Hariga M. , (1995) An EOQ model for deteriorating items with shortages and time-varying demand. J of Operational Res Socty,46, 398-404

[7]. Mondal B., Bhunia A.K and Maiti M.,(2003), An inventory system of ameliorating items for price dependent demand rate, Comps and Inds Engg,45(3),443-456

[8]. Mishra V.K and Singh L.S.,(2010) Deteriorating inventory model with time dependent demand and partial backlogging, App Math Sci 4(72), 3611-3619

[9]. Mohan R and Venkateswarlu R.,(2013a) Inventory Management Models with Variable Holding Cost and Salvage Value, IOSR J. of Busi. and Mgmt (IOSR-JBM), Vol.12(3), pp. 37-42

[10]. Mohan R and Venkateswarlu R.,(2013b), Inventory Management Model with Quadratic Demand, Variable Holding Cost with Salvage value, Res. Journal of Management Sci,Vol.2(2),1-10 December

[11]. Mohan R and Venkateswarlu R.,(2014c) Inventory Model for Time Dependent Deterioration, Time Dependent Quadratic Demand and Salvage Value (J of In. Math.Socy, (2014) Journal of the Indian math. Soc, Vol 81,Nos 1-2 (2014) 125-146

[12]. Sushil Kumar, U.S. Rajput ,(2013), An inflationary Inventory Model for Weibull Deteriorating Items with Constant Demand and Partial Backlogging Under Permissible Delay in Payments American Journal of Engineering Research( AJER) Vol 02, Issue -09 PP-46-54

[13]. Vinod Kumar Mishra,(2012), Inventory model for time dependent holding cost and deterioration with salvage value and shortages. The Jour of Math and Comp Sci Vol. 4 No.1 (2012) 37-47

[14]. Venkateswarlu R, and Mohan R.,(2013), An Inventory Model for Time Varying Deterioration and Price Dependent Quadratic Demand with salvage value, Ind. J. of Computational and Appld Math., Vol.1, No.1(2013), PP 21-27 (2013a)

[15]. Venkateswarlu R, and Mohan R.,(2013) An Inventory Model with Weibull Deterioration, Time Dependent Quadratic Demand and Salvage Value, AIMS -10, International Conference (2013b) Bangalore 